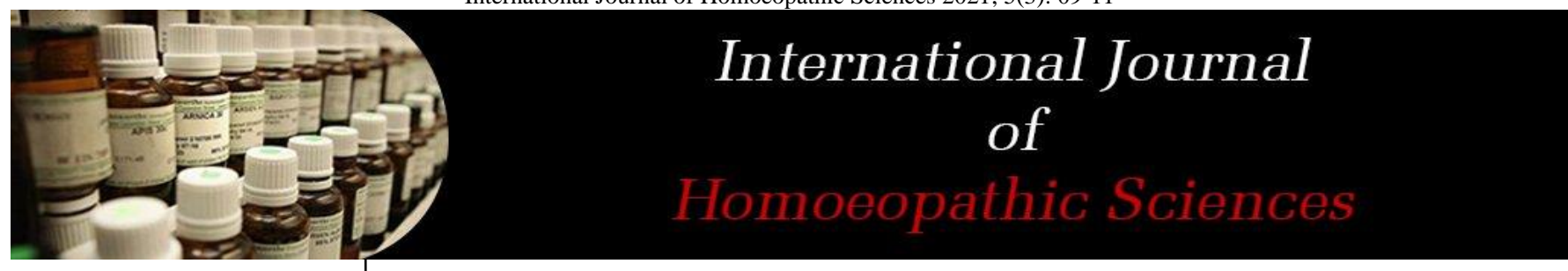

E-ISSN: 2616-4493 P-ISSN: 2616-4485 www.homoeopathicjournal.com IJHS 2021; 5(3): 09-11

Received: 07-05-2021

Accepted: 09-06-2021

Dr. Hasina M Mhaishale HOD, Professor, Department of OBGY, Parul Institute of Homoeopathy and Research, Vadodara, Gujarat, India

Dr. MA Mhaishale HOD, Professor, Repertory, Parul Institute of Homoeopathy and Research, Vadodara, Gujarat, India
Corresponding Author: Dr. Hasina M Mhaishale HOD, Professor, Department of OBGY, Parul Institute of Homoeopathy and Research, Vadodara, Gujarat, India

\section{Role of homoeopathy in perinatal mortality}

\author{
Dr. Hasina M Mhaishale and Dr. MA Mhaishale
}

DOI: $\underline{\text { htps://doi.org/10.33545/26164485.2021.v5.i3a.395 }}$

\section{Abstract}

60-120 per 1000 is the approximate perinatal mortality in India though the exact number is unknown. The aetiology of stillbirth is varies and is unknown in 20-30\% cases. The following study has been done in an effort to obtain the detailed understanding of incidence of perinatal mortality, to analyze the different aetiological factors and utility of various homeopathic remedies for its prevention and low incidence. The results of this research, demonstrate that case taking of the patients play important role in suggesting the probable reasons of the prenatal mortality which could be prevented if homeopathy is instilled during early stages. At the end of the study, it was found that $65 \%$ of the cases have been recovered completely, in $10 \%$ cases no improvement was seen while $25 \%$ of the cases showed partial improvement.

Keywords: perinatal mortality, stillbirth, case-taking, antepartum, postpartum, arsenic album, helonias

\section{Introduction}

Perinatal Mortality is also known as perinatal deaths referred to the death of a fetus or neonate.

WHO defines Perinatal mortality as, "Number of stillbirths and deaths in the first week of life per 1000 total births, the perinatal period commences at 22 completed weeks (154 days) of gestation and ends seven completed days after birth.

PNMR is one of the important indicators of the health status of given Society.

The etiology of stillbirth is varied and unknown in $20 \%-30 \%$ of the cases. Some causes like pregnancy induced hypertension (PIH), perinatal Hypoxia and infections are preventable. Causes like Syphilis are no longer a problem and perinatal deaths due to cord accidents have remained almost unchanged. Due to inadequate nutrition, antenatal care so as to have early recognition of at risk pregnancy magnitude of PNM is still very large in our country.

\section{Incidence}

Despite the tremendous advances in modern obstetric practice Perinatal mortality is high. In developed countries rate for babies over 1000gm is less than 6/1000 births and PNMR ranges from 30 to 200 . In India apparently between $60-120 / 1000$ and about $30-40 \%$ infants born in India or LBW $(<2500 \mathrm{gm}$ at birth) and about $85 \%$ of all neonatal deaths occur among them.

\section{Etiological factors}

\section{Antepartum causes}

1. Maternal

a. Pregnancy complications - Pregnancy induced hypertension and eclampsia. Antepartum Hemorrhage (APH).

b. Persistent medical illness in pregnancy - chronic hypertension, diabetes, anaemia, Syphilis intrauterine factors, maternal trauma, obstructed labour or rupture of uterus.

\section{Fetal factors}

a. Heamolytic diseases

b. Post maturity

c. Cord accident

d. Congenital malformation and chromosomal abnormalities

e. Unexplained 


\section{Intrapartum causes}

1. Malpresentation

2. Hypoxia

3. Birth trauma

\section{Postpartum causes}

1. Prematurity

2. Perinatal asphyxia

3. Low birth weight

4. Neonatal sepsis

From all these causes prematurity, low birth weight, prolonged labour, premature rupture of membrane, chorioamnionitis and intrapartum hypoxia have been identified as substantial risk factors.

Maternal under nutrition, closely spaced pregnancy, severe anaemia, adolescent pregnancy, antenatal infections, heavy workload, and maternal hypertension are the risk factors LW babies.

\section{Homeopathic approach}

In PNM our objective is to simply call attention to the profound importance of most carefully treating the disorders incident to the pregnancy. Even in cases where there severity does not entail

suffering they may be seen to afford the most precious opportunities for permanently improving the health of the mother and of rendering her confinement comparatively comfortable and perfectly safe with surviving the preservation of health of the offspring and finally securing the comfort of both mother and child during lactation.

Most valuable and efficient remedies for the disorders incident to pregnancy will be found among the entipsorics and in some cases the higher these are given the more good will they do is my own experience.

\section{Therapeutics}

Remedies for different pregnancy induced diseases in Mother

1. For PIH - Apismel, Ars. Alb., Baryt. mur. Bell. Glonoine, Helonias, Cuprum met., Cicuta. Ver.

2. For Anaemia - Ferrum met., Pulsatilla, Calc. carb, Ars. Alb., Halonias, Sec. cor., Nat. mur.

3. For APH - Melifollium, Ipecac., Hamammelis, Trillium, Sabina.

4. For labour - Caulophyllum, Actea. rac., Gels., Cham., Arnica, Coffea, Platina.

\section{In infants}

1. Neonatal asphyxia - Chlorum, Sambucus, Camphora, Ant. tart., Brom., Aethusa, Arg. nit., Ars. alb., Bell., Calc. carb.

2. For cyanosis - Aconite, Arnica, Calc. carb., Carb. veg., China., Digitalis, Lachesis, Laurocerasus, Sec. cor.

3. For Jaundice - Lupulushum., Aconite, Ars. alb., Bryo., Calc. carb., Cham., China., Ipecac, Merc. sol., Nux. Vom., Sulph.

4. For convulsion - Ars. alb, Bell, Causticum, Cham., Cicuta. Ver., Hyos., Opium, Sec. cor.

\section{Design of study}

- To study the risk factors and analysis of different aetiological factors responsible for perinatal mortality and its percentage.

- Establishing homeopathic remedies as shortest method of treatment in preventing perinatal deaths and minimizing perinatal mortality rate.

\section{Strategies and Methodology}

Strategies to reduce perinatal and neonatal mortality

- Improving standard of living and raise the social status of women.

- Universal parental care for all pregnant mothers.

- Approach to identify high risk pregnancy and timely transfer to suitable centers.

- Raise the standard of care during parturition.

- Establish liaison between domiciliary care provider and institutions.

- Provide easily accessible neonatal care services.

\section{Care of full term new born infant}

- Care after birth - Newborn should be weighed, observe all vital signs and see for any signs cyanosis or excessive mucous secretion.

- Umbilical cord - A satisfactory compromise is to clamp the cord immediately when the infant's condition is poor or otherwise to leave it until the pulsations of the cord have ceased. Cord vessels should be inspected.

- Bathing - LBW babies who need special care should not be bathed immediately after birth. Meconium and vermix should gently be wiped out soon after birth.

- Detailed physical examination concerned with eyes, weight, passage of stool, urine, and foreskin should be done. Immunization should be done.

\section{Material and Method}

1. Total 30 cases were treated and taken into consideration for present study.

2. While detailed case taking, the primary focus was on the following:

- Obstetrichistory: History of consanguineous marriages, premature delivery and history of previous stillbirth/neonatal deaths

- Type of delivery

- Detail delivery notes

- Examination of baby and placenta

- Condition of baby immediately after birth and during early neonatal period

3. Patients from Savitribai Phule KMC Hospital, Kolhapur and from OPD, IPD and rural camps of SJPE's HMC, Kolhapur.

4. After detail case taking, data was obtained from patients, their attendants and clinical examination.

\section{Observation table and Results}

All cases were followed for the period of 3 to 6 months and considered for statistical study.

Table 1: Mortality in relation to age group of mother

\begin{tabular}{|c|c|c|c|}
\hline Sr. No. & Age group & No. of cases & \% of Improvement \\
\hline 1 & $20-25$ & 13 & 55 \\
\hline 2 & $25-30$ & 12 & 85 \\
\hline 3 & $30-35$ & 5 & 50 \\
\hline
\end{tabular}

Table 2: Mortality in relation to the sex of the baby

\begin{tabular}{|c|c|c|c|}
\hline Sex of baby & $\begin{array}{c}\text { Total no. of } \\
\text { deliveries }\end{array}$ & $\begin{array}{c}\text { No. of cases not } \\
\text { improved }\end{array}$ & $\begin{array}{c}\text { \% Perinatal of } \\
\text { mortality }\end{array}$ \\
\hline Female & 12 & 3 & 25 \\
\hline Male & 18 & 7 & 39 \\
\hline
\end{tabular}


Table 3: Conclusive statistic

\begin{tabular}{|c|c|c|}
\hline Sr. No. & Cases & Percentage \\
\hline 1 & Improved cases & $65 \%$ \\
\hline 2 & Non improved cases & $10 \%$ \\
\hline 3 & Partially improved & $25 \%$ \\
\hline
\end{tabular}

\section{Result and Discussion}

The study was carried out on 30 patients from Antenatal and during labor. Majority of cases are with antenatal complications. After detailed history regarding mentals, obstetric history, past history, examinations, labour notes and fetal examination homoeopathic similimum was prescribed.

While dealing with ANC complication remedies like Apis. mel., Caulophyllum and Nat, mur. was frequently used and in cases of Neonatis remedies like Ant. tart., Chamomilla, Sambucus, Chlorum, Arnica and Bromium were found to be effective.

\section{Conclusion}

At the end of the study, it was found that $65 \%$ of the cases have been recovered completely. In $10 \%$ cases there was no improvement seen. $25 \%$ of the cases showed partial improvement (i.e. IUGR). This proves that Homeopathy is highly efficient in preventing perinatal Mortality.

\section{References}

1. Mehta Ajit, Jayant K. Perinatal Mortality in India: Jr. Ob. \& Gy. Ind 1981;31:183.

2. Suraj Gupta, Bakul Parekh J. The short textbook of Pediatrics, $13^{\text {th }}$ edition Jaypee Medical Publication 2020, P11-13.

3. Singh Meharban. Hospital based data on perinatal \& neonatal mortality in India: Ind. Ped 1986;23:579.

4. Dr. Choudhari NM. A study on Materia Medica, Publisher - B. Jain 2001, P71, 99, 149, 475, 836,919.

5. Allen HC. Allen's Keynotes \& Rearranged \& Classified of leading remedies of the Materia Medica \& Bowel Nosodes including Repertorial Index, $10^{\text {th }}$ edition, Publisher - B. Jain 2005, P6, 40, 89, 97, 105, 157, 206, 315.

6. Clerke JH. A dictionary of practical Materia Medica, Vol. I to III, Publisher - B. Jain. Reddy SR. Effect of homoeopathic medicine Lycopodium clavatum in urinary calculi. International Journal of Applied Research 2017;3(1):790-1. P15, 453,753, 866, 890.

7. James Tyler Kent. Lectures on Homoeopathic Materia Medica., Indian Book \& Periodicals Syndicate Publisher 2015, P193, 276, 438, 496.

8. Henry Guernsey N. The applications and principles of and practice of homoeopathy to Obstetrics \& the disorders peculiar to women and young children, reprint edition,, Publisher - B. Jain 1990, P148, 378.

9. William Boericke. Pocket Manual of Homoeopathic Materia Medica with Indian medicine $\&$ repertory, $9^{\text {th }}$ edition, Indian Book \& Periodicals Publisher 2016, P181, 199, 201, 336, 396, 408, 477, 486.

10. Vinod Paul K, Arvind Bagga. GHAI Essential Pediatrics, 8th edition, CBS publisher \& developer 2013, 124.

11. Bajpai B, Rajgopal KC. Observations on perinatal mortality: Ind. Ped 1966;3(3):83.

12. Singhal PK, Mathur AP. Neonatal morbidity \& mortality in ICDS urben slums: INd. Ped 1990;27:485.
13. Sheila Karan, Bhagwan. Incidence and causes of perinatal mortality at the Institute of Child health, Niloufer Hospital, Hyderabad - A. P.: INd. Ped 1972;9(2):99.

14. Dr. Phatak SR. Materia medica of Homoeopathic medicine, $2^{\text {nd }}$ edition, Publisher - B. Jain 1999, P151, 237, 498, 581, 615, 639.

15. Carroll Dunham. Lectures on Materia Medica, $5^{\text {th }}$ edition, Publisher - B. Jain 2014, P57, 138, 169, 266, 338, 346 .

16. DC Dutta, Hiralal Konar. DC Dutta's Textbook of Obstetrics, $8^{\text {th }}$ edition, JAYPEE The Health Sciences Publisher 2015, P687, 688, 689. 